\title{
Revisiting the Chemistry and Kinetics of Sphalerite Activation with Cu(II): A Contact Angle Study
}

\author{
G.I. Dávila-Pulido, A. Uribe-Salas* and F. Nava-Alonso
}

CINVESTAV-IPN Unidad Saltillo, Carr. Saltillo-Monterrey km 13, Col. Molinos del Rey Ramos Arizpe, Coahuila, C.P. 25900, México.

\begin{abstract}
This paper presents results of a contact-angle study performed to revisiting the chemistry and kinetics of sphalerite activation with $\mathrm{Cu}(\mathrm{II})$ on the light of the contact angle technique. Sphalerite $(\mathrm{ZnS})$ activation is conducted with the aim of developing a cuprous sulfide layer with chemical affinity toward thiol-type collectors. This is achieved by manipulating the concentration of $\mathrm{Cu}(\mathrm{II})$, the conditioning time and the $\mathrm{pH}$ of the flotation slurry. The chemistry of the reaction consists of the reduction of $\mathrm{Cu}(\mathrm{II})$ to $\mathrm{Cu}(\mathrm{I})$ while copper replaces zinc from the external layers of the mineral crystal, to form a cupric sulfide $(\mathrm{CuS})$ which spontaneously transforms to cuprous sulfide $\left(\mathrm{Cu}_{2} \mathrm{~S}\right)$ and polysulfide $\left(\mathrm{S}_{\mathrm{n}}{ }^{2-}\right)$, rendering the activated sphalerite hydrophobic. The activation process follows a second-order kinetics in which the apparent controlling step is the adsorption of $\mathrm{Cu}(\mathrm{II})$ on the unreacted mineral surface.
\end{abstract}

Keywords: Activation, chemistry, contact-angle, kinetics, sphalerite.

\section{INTRODUCTION}

\section{Chemistry of Sphalerite Activation}

The major source of metallic zinc is in the form of a sulfide mineral termed sphalerite. Sphalerite is concentrated by froth flotation where it is separated from both non-sulfide gangue (e.g., silica) and sulfide-gangue (e.g., pyrite) due to the hydrophobic properties which is achieved by activation with copper and reaction with thiol-type collectors. Sphalerite activation with $\mathrm{Cu}(\mathrm{II})$ has been extensively studied and to date it has been established that it exists according to the following ionic exchange mechanisms $[1,2]$.

$$
\begin{aligned}
& \mathrm{ZnS}_{(\text {surface })}+\mathrm{Cu}^{2+}{ }_{(a q)} \rightarrow \mathrm{CuS}_{(\text {surface })}+\mathrm{Zn}^{2+}{ }_{(a q)} \\
& \text { Or } \times \mathrm{ZnS}+\mathrm{Cu}^{2+}{ }_{(a q)} \rightarrow(\mathrm{ZnS})_{x-1} \mathrm{CuS}+\mathrm{Zn}^{2+}{ }_{(a q)}
\end{aligned}
$$

The $\mathrm{Cu}$ (II) of the cupric sulfide $\mathrm{CuS}$ reduces to $\mathrm{Cu}(\mathrm{I})$ oxidizing the sulfide to polysulfide (an hydrophobic species), according to the following equation [2]:

$2 n \mathrm{CuS}+2 e^{-} \rightarrow n \mathrm{Cu}_{2} \mathrm{~S}+\mathrm{S}_{n}^{2-}$

An alternative stochiometry, which does not require the participation of an electron-donor reaction, is:

$10 \mathrm{CuS} \rightarrow 4 \mathrm{Cu}_{2} \mathrm{~S}+\mathrm{Cu}_{2} \mathrm{~S}_{6}$

where $\mathrm{Cu}_{2} \mathrm{~S}_{6}$, the copper polysulfide that is probably obtained $[1,9]$, is responsible for the hydrophobic character of $\mathrm{Cu}(\mathrm{II})$ activated sphalerite.

*Address correspondence to this author at the CINVESTAV-IPN Unidad Saltillo, Carr. Saltillo-Monterrey km 13, Col. Molinos del Rey Ramos Arizpe, Coahuila, C.P. 25900, México; Tel: 52(844)438-9600, Ext: 9644;

Fax: 52(844)438-9610; E-mail: alejandro.uribe@cinvestav.edu.mx
The new surface displays "natural" hydrophobicity owing to the presence of the polysulfide, as well as chemical affinity towards thiol-type collectors as xanthate (alkyl dithiocarbonate) due to the presence of $\mathrm{Cu}(\mathrm{I})$ sulfide.

\section{Modeling the Activation Kinetics}

The kinetics of activation has been studied by several researchers, and currently there is agreement in the two stage nature of the activation reaction: the first, which is limited to the formation of few monolayers, depending on the characteristics of the activating solution such as copper concentration and $\mathrm{pH}$, variables that control the mass transfer rate in the liquid phase, while during the second stage, the reaction occurs with a decreasing rate and last as long as the solid and solution are in contact [3]. Based on experimental observations, there is agreement in the sense that the chemical reaction is not the rate controlling step of the kinetics; otherwise, the kinetics would apparently be of zero order and would not depend on either copper concentration or availability of nonreacted surface on sphalerite particles. It has been claimed that one of the models that better describes sphalerite activation with copper, considers that copper adsorption on the mineral surface is the rate controlling step (i.e., the chemical reaction is fast [3]). This implies that in acid or slightly acid solutions where the cation $\mathrm{Cu}^{2+}$ is the predominant $\mathrm{Cu}$ (II) species, the reaction rate must be proportional to both the concentration of the adsorbing species (i.e., $\mathrm{Cu}^{2+}$ ) and to the fraction of mineral surface that has not reacted (i.e., has not adsorbed $\left.\mathrm{Cu}^{2+}\right)$. The following second order equation represents this situation:

$$
\frac{d A}{d t} \propto\left[\mathrm{Cu}^{2+}\right][\mathrm{Zn}]_{\text {surface }}
$$


where $A$ is the amount of $\mathrm{Cu}^{2+}$ adsorbed on the sphalerite surface, $\left[\mathrm{Cu}^{2+}\right]$ is the concentration of $\mathrm{Cu}^{2+}$ in the solution, and $[\mathrm{Zn}]_{\text {surface }}$ is the "concentration" of $\mathrm{Zn}$ sites in the sphalerite external layers that undergo ionic exchange, and that have not been replaced by $\mathrm{Cu}$ ions at time $\mathrm{t}$.

A mass balance of $\mathrm{Cu}(\mathrm{II})$ allows to express $\left[\mathrm{Cu}^{2+}\right]$ with the following equation:

$\left[\mathrm{Cu}^{2+}\right]=\left[\mathrm{Cu}^{2+}\right]_{0}-\mathrm{A}$

where $\left[\mathrm{Cu}^{2+}\right]_{0}$ is the initial concentration of copper in the solution.

Similarly, $[\mathrm{Zn}]_{\text {surface }}$ can be expressed as follows:

$[\mathrm{Zn}]_{\text {surface }}=A_{\infty}-A$

where $\mathrm{A}_{\infty}$ is the maximum amount of $\mathrm{Cu}^{2+}$ that may be adsorbed on the sphalerite external layers.

By solving equations (3) to (5), the kinetic model proposed by Finkelstein [3] is obtained:

$k t=\frac{1}{\left[C u^{2+}\right]_{O}-A_{\infty}} \log \left(\frac{A_{\infty}\left(\left[C u^{2+}\right]_{o}-A_{\infty}\right)}{\left[C u^{2+}\right]_{O}\left(A_{\infty}-A\right)}\right)$

Where $\mathrm{k}$ is the rate constant.

The experimental methodology used in this work is based on the contact angle that the hydrophobised mineral immersed in an aqueous solution establishes with an air bubble. To convert contact angle to $\mathrm{Cu}^{2+}$ adsorption, it is postulated that there is a linear relationship between the rate of development of the contact angle ( $\mathrm{d} \theta / \mathrm{dt})$ and the rate of adsorption of $\mathrm{Cu}^{2+}$ on the sphalerite surface (i.e., $\mathrm{dA} / \mathrm{dt}$ ):

$\frac{d \theta}{d t} \propto \frac{d A}{d t}$

Equation (7) states that the rate at which the contact angle increases is proportional to the rate at which $\mathrm{Cu}^{2+}$ chemisorbs on the mineral surface; since the chemical reaction is not the rate limiting step [3], the rate of hydrophobization is given by the adsorption rate.

In turn, the "concentration" of $\mathrm{Zn}$ sites remaining in the unreacted upper layers of the mineral may be given by:

$[Z n]_{\text {surface }} \propto\left(\theta_{\infty}-\theta\right)$

where $\theta$ and $\theta_{\infty}$ are the contact angles at time $\mathrm{t}$ and $\mathrm{t} \rightarrow \infty$ (the maximum angle that is experimentally achieved), respectively. At time zero, $\theta$ (equals to zero) corresponds to a maximum concentration of zinc sites on the surface of sphalerite, while at infinite time, $\theta\left(=\theta_{\infty}\right)$ corresponds to a zinc depleted surface.

Equation (3) simplifies to $\left[\mathrm{Cu}^{2+}\right] \approx\left[\mathrm{Cu}^{2+}\right]_{\text {o }}$ since $A$, the amount of $\mathrm{Cu}^{2+}$ adsorbed at time $\mathrm{t}$, may be considered negligible compared to the initial copper concentration used.

Finally, Equations (3) to (5) are solved incorporating the above considerations, to give:

$\theta=\theta_{\infty}\left(1-10^{-k\left[\mathrm{Cu}^{2+}\right]_{o} t}\right)$
The objective of this work is to investigate the role of copper activation on the development of the hydrophobic character of sphalerite as well as the chemistry and kinetics of the process. Of particular concern is the role of $\mathrm{pH}$ since it defines the nature of the activating copper species. Knowledge of the activation kinetics is used to assist in the designing of the conditioning stage of zinc flotation circuits, in order to allow for sufficient residence time of the flotation pulp to achieve the desired sphalerite activation.

\section{EXPERIMENTAL PART}

\section{Minerals and Reagents}

The sphalerite crystals used in this work were obtained from the Bismark mining district (Ascensión, Chih., México). The mineral was characterized by X-ray diffraction and atomic absorption spectrometry. The sphalerite contained about $59.1 \% \mathrm{Zn}, 29.1 \% \mathrm{~S}, 5.7 \% \mathrm{Fe}$ in solid solution and around $6 \%$ insoluble. Cupric sulfate pentahydrate $\left(\mathrm{CuSO}_{4} \cdot 5 \mathrm{H}_{2} \mathrm{O}\right)$ reagent grade was used to activate sphalerite. To regulate the $\mathrm{pH}, 1 \mathrm{~N}$ solutions of $\mathrm{NaOH}$ and $\mathrm{HNO}_{3}$ reagent grade were used.

\section{Contact Angle Measurement Technique}

The techniques to measure contact angle on mineral surfaces may be divided into two groups: those applicable to flat and smooth surfaces (e.g., the captive bubble method), and those used for particulate materials (e.g., capillary penetration method). The most popular method for measuring contact angle is the captive bubble, mainly due to the simplicity of the technique, whose main advantages are: only very small quantities of liquid are required and solid surfaces as small as a few square millimeters can be used [4].

To perform the contact angle experiments reported in this paper, the sphalerite crystals were manually selected and mounted in metallographic resin; the samples were ground and polished according to the technique reported in the literature [4]. This technique consists of grinding and polishing the crystal with silicon carbide paper (No. 80 to 800 ) under deionized and deoxygenated water to avoid contamination and oxidation of the mineral surface as much as possible. After polishing, the sample was placed in an ultrasonic bath in order to remove abrasives remaining on the mineral surface; it is important to note that this stage of sample preparation was conducted prior to each test in order to renew the mineral surface. Once the mineral sample preparation finished, the conditioning was carried out with the changing residential time and chemical conditions of interest (copper concentration and $\mathrm{pH}$ ), which approximately simulated the conditions of industrial sphalerite flotation circuits. Upon completion of the conditioning process, the sample was transferred to an acrylic box containing $10^{-3} \mathrm{M} \mathrm{NaNO}_{3}$ aqueous solution at $\mathrm{pH} 9$, where the crystal was contacted with an air bubble of diameter about $1 \mathrm{~mm}$, produced with a Hamilton digital syringe (Mod. 705RN), immediately proceeding to take the photographs of the contact of the three phases (see Fig. 1). The photographs were finally analyzed with the help of an image analysis program (Image-Pro 5.1) to obtain the contact angle. The experiments were performed in tripli- 


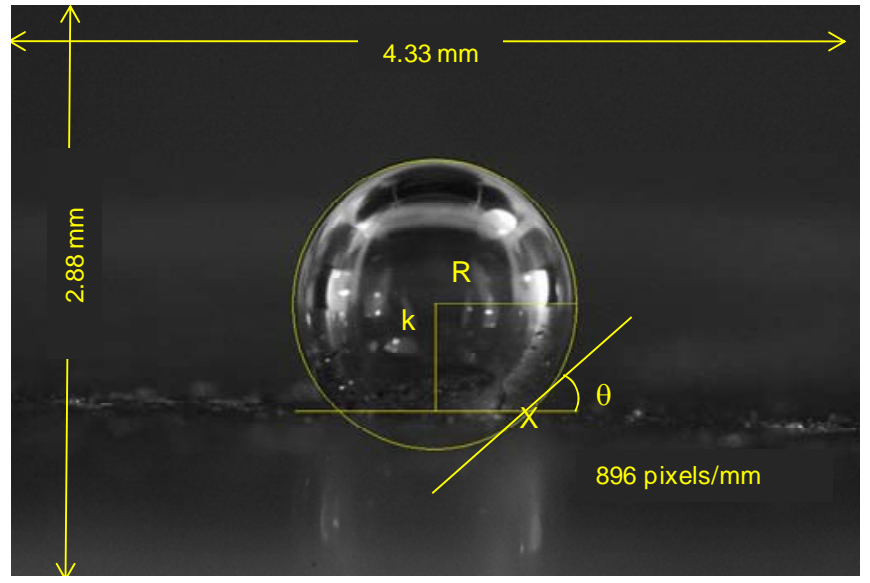

Fig. (1). Photograph that illustrates the methodology used to estimate the slope to the circle in the point of the three-phase contact (x).

cate and therefore, the value reported is the average of the three measurements, while the error bars delimit the $99 \%$ confidence interval of the t-student distribution.

\section{RESULTS AND DISCUSSION}

The activation of sphalerite involves the reaction between the copper adsorbed on its surface and the sulphide of the mineral lattice, and may occur by two distinct mechanisms, depending on the $\mathrm{pH}$ of the solution, ionic exchange and superficial precipitation. Sphalerite activation was evaluated at $\mathrm{pH} 5.4$, where the predominant species is $\mathrm{Cu}^{2+}$, and at $\mathrm{pH}$ 9 , where the predominant species is $\mathrm{Cu}(\mathrm{OH})_{2}$, as shown in the species distribution diagram of Fig. (2). For both the cases copper concentration was varied between 0 and $50 \mathrm{mg} / \mathrm{L}$, while conditioning time was varied from 0 to $25 \mathrm{~min}$ for $\mathrm{pH}$ 5.4 and from 0 to $60 \mathrm{~min}$ for $\mathrm{pH} 9$.

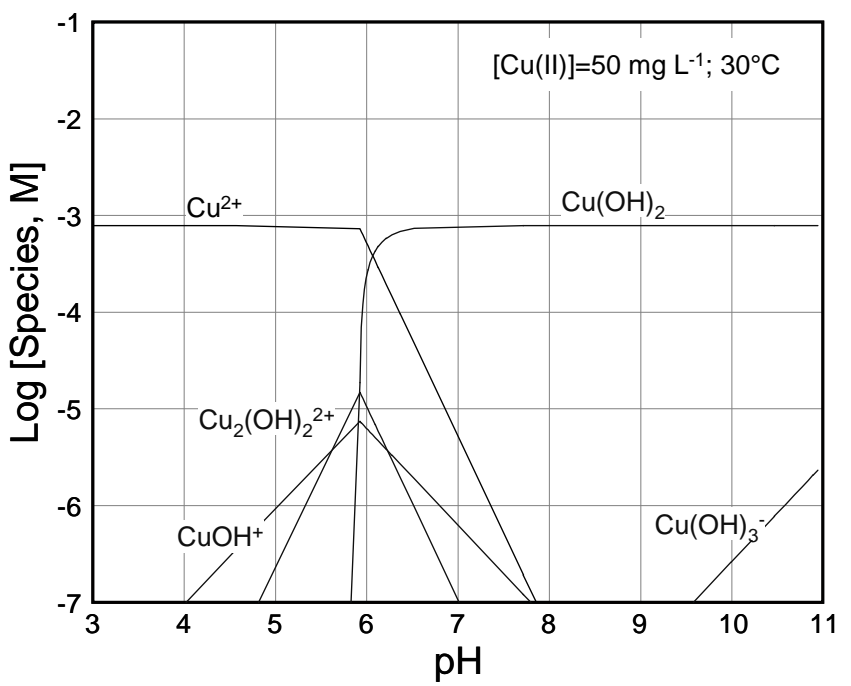

Fig. (2). Species distribution diagram of the $\mathrm{Cu}(\mathrm{II})-\mathrm{H}_{2} \mathrm{O}$ system at $25^{\circ} \mathrm{C}$ for a $\mathrm{Cu}(\mathrm{II})$ concentration of $50 \mathrm{mg} / \mathrm{L}$, showing the predominance of $\mathrm{Cu}^{2+}$ at $\mathrm{pH}$ below 6 and the predominance of $\mathrm{Cu}(\mathrm{OH})_{2}$ above this pH (HSC Chemistry v. 5.11).

\section{Sphalerite Activation with $\mathrm{Cu}^{2+}$}

Fig. (3). presents the effect of copper concentration on the contact angle developed by sphalerite at $\mathrm{pH} 5.4$ for two conditioning times, 5 and $15 \mathrm{~min}$. It is observed that both copper concentration and conditioning time play important roles in the development of hydrophobic properties by sphalerite owing to the formation of hydrophobic species on its surface, namely, a polysulfide or elemental sulfur, according to the mechanisms described by Equations (1) and (2). This phenomenon may be thermodynamically modeled considering metastable conditions for the oxidation of the sulfide [5] by means of available software (HSC Chemistry v. 6.0). Fig. (4) shows the results obtained when $1 \mathrm{~g}$ of $\mathrm{ZnS}$ is contacted with 1 liter of an aqueous solution at $30^{\circ} \mathrm{C}$, containing

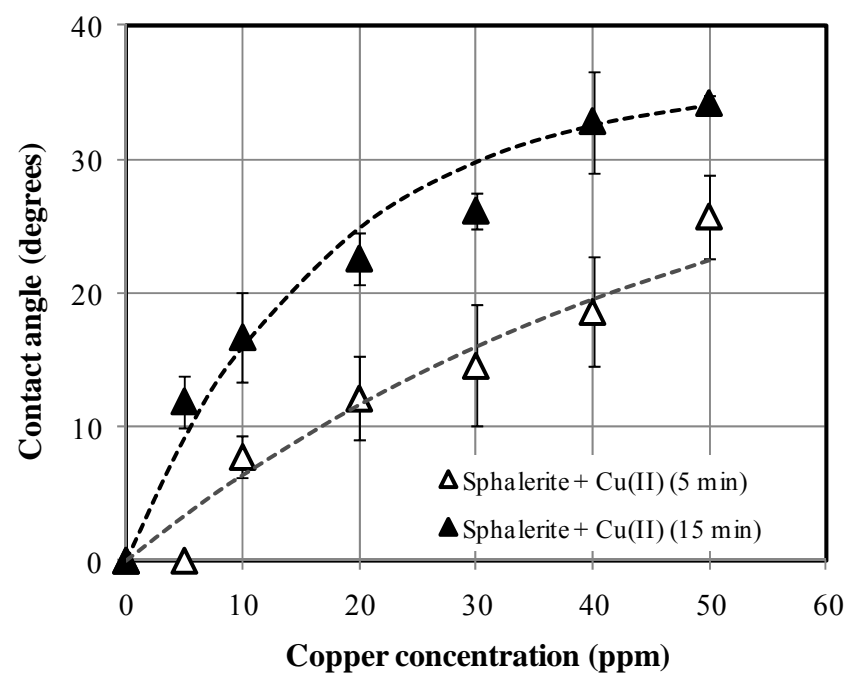

Fig. (3). Effect of $\mathrm{Cu}^{2+}$ concentration and conditioning time on the contact angle of sphalerite. The tests were carried out at $30^{\circ} \mathrm{C}$, natural $\mathrm{pH}$ (5.4) and $10^{-3} \mathrm{M} \mathrm{NaNO}_{3}$ ionic strength; the contact angle was measured at $\mathrm{pH} 10$. The dotted lines were obtained with Equation (9), developed in this work.

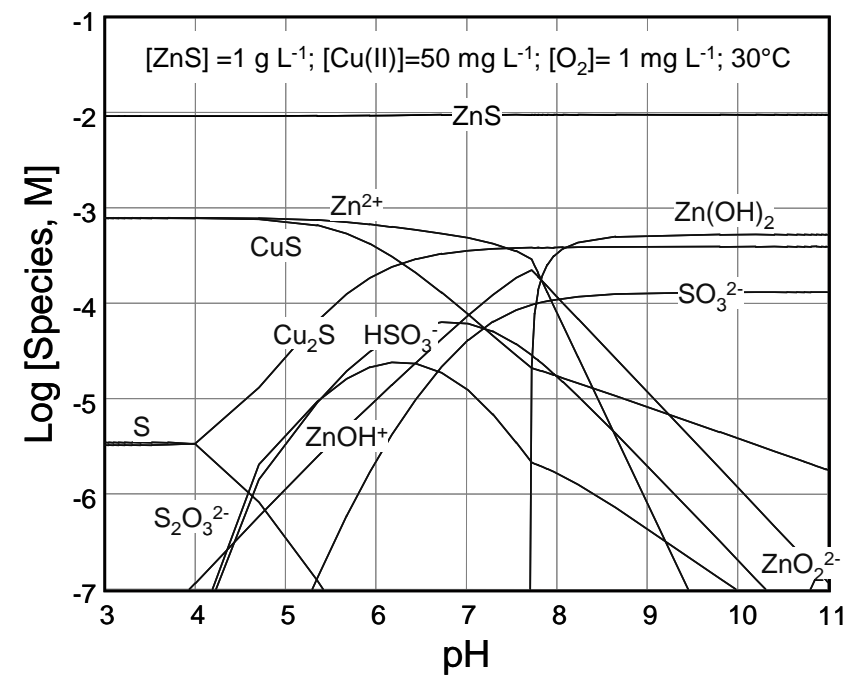

Fig. (4). Species distribution diagram for the activation of $\mathrm{ZnS}$ with $\mathrm{Cu}$ (II) at $30^{\circ} \mathrm{C}$, when considering a solution relatively free of dissolved oxygen and the metastable products of the oxidation of sulphide [5]. HSC Chemistry v. 5.11. 
$50 \mathrm{mg} \mathrm{L}^{-1}$ of copper and $1 \mathrm{mg} \mathrm{L}^{-1}$ of dissolved oxygen (i.e., relatively free of dissolved oxygen). The figure shows that at $\mathrm{pH}$ 5.4, the major copper sulfide is covellite (CuS) and that cuprous sulfide $\left(\mathrm{Cu}_{2} \mathrm{~S}\right)$ and minor amounts of elemental sulfur (S) are also present. As expected, zinc is displaced from the mineral by copper and remains in solution as the cation $\mathrm{Zn}^{2+}$.

Fig. (5) presents the effect of conditioning time on the contact angle achieved when using a concentration of $50 \mathrm{mg}$ $\mathrm{L}^{-1}$ of $\mathrm{Cu}^{2+}$. The results show that contact angle increases as time increases, approaching a maximum value that may be dictated by the chemical equilibrium and that most probably corresponds to $\theta_{\infty}$ of Equation (9). By fitting the experimental results in Fig.(3 and 5) to Equation (9) making use of the least squares method, the value of $\mathrm{k}$ and $\theta_{\infty}$ that give the best fit are obtained as $0.0017 \mathrm{~L} \mathrm{mg}^{-1} \mathrm{~min}^{-1}$ and $36^{\circ}$, respectively. The dotted lines in the figures correspond to Equation (9) with the above values of $\mathrm{k}$ and $\theta_{\infty}$. A fairly good correlation between the experimental data and the equation is observed, which suggests that the activating reaction obeys a second order kinetics.

Additionally, the figures show that apparently the activation takes place in two steps which depend on the concentration of copper in solution, the available sphalerite surface to exchange ions and time. Similar results have been reported in the literature $[6,7]$, indicating that in the first stage, that occurs in the first five minutes, the kinetics depends on the $\mathrm{pH}$ and copper concentration, while during the second stage, controlled by lattice diffusion, the kinetics is substantially slower.

\section{Sphalerite Activation with $\mathrm{Cu}(\mathrm{OH})_{2}$}

Fig. (6) presents the effect of $\mathrm{Cu}(\mathrm{II})$ concentration (as $\left.\mathrm{Cu}(\mathrm{OH})_{2}\right)$ on the contact angle of sphalerite conditioned 15 min at $\mathrm{pH}$ 9. As observed in Fig. (4), at this $\mathrm{pH}$ the major copper sulfide is chalcocite $\left(\mathrm{Cu}_{2} \mathrm{~S}\right)$ with minor amounts of covellite (CuS). The zinc replaced by copper from the min-

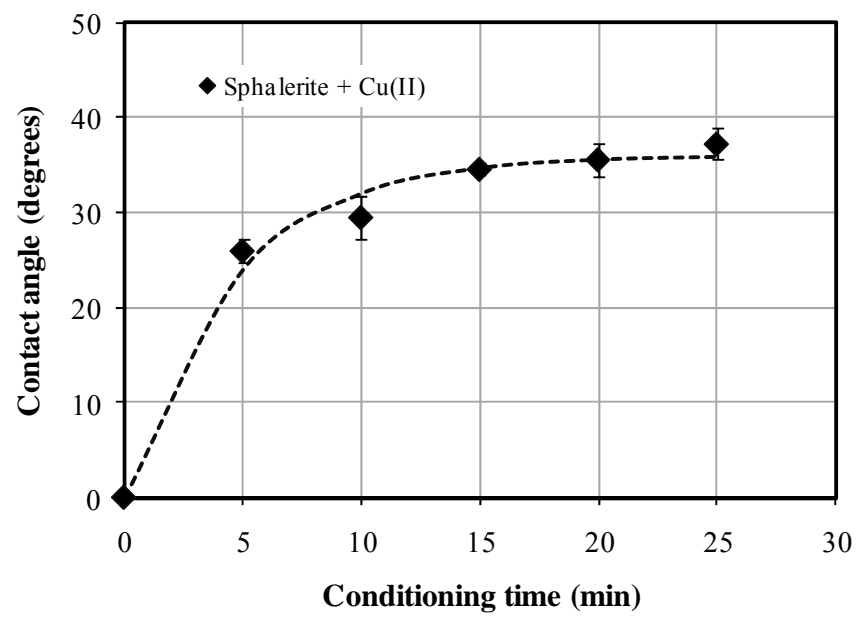

Fig. (5). Effect of conditioning time on the development of the hydrophobic properties of sphalerite. The tests were carried out at $30^{\circ} \mathrm{C}$ and $10^{-3} \mathrm{M} \mathrm{NaNO}_{3}$. Conditioning was performed at natural $\mathrm{pH}$ (5.4), and the contact angle was measured at $\mathrm{pH} 10$. The dotted line was obtained with Equation (9).

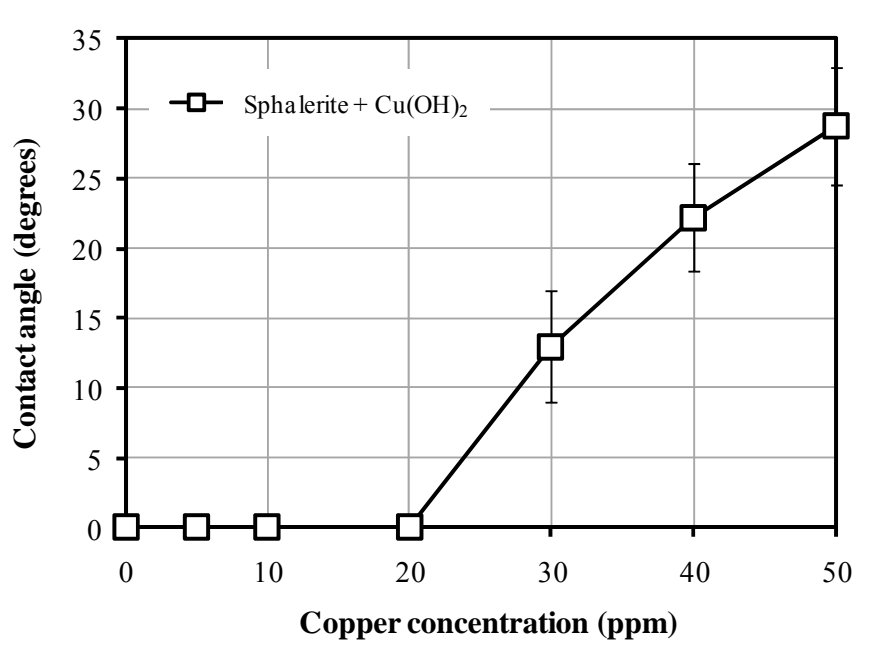

Fig. (6). Effect of $\mathrm{Cu}$ (II) concentration as $\mathrm{Cu}(\mathrm{OH})_{2}$, on the contact angle of sphalerite as a function of conditioning time. The tests were carried out at $30^{\circ} \mathrm{C}$, $\mathrm{pH} 9$ and $10^{-3} \mathrm{M} \mathrm{NaNO}_{3}$ ionic strength.

eral lattice is present as hydroxide $\left(\mathrm{Zn}(\mathrm{OH})_{2}\right)$ and therefore, may counteract the hydrophobic character of the surface. Fig. (6) shows that contact angles of zero degree are observed for copper concentrations of $20 \mathrm{mg} \mathrm{L}^{-1}$ and below; when larger concentrations are used, the contact angle increases linearly up to a value of about $28^{\circ}$ for $50 \mathrm{mg} \mathrm{L}^{-1}$ of $\mathrm{Cu}(\mathrm{II})$. The results reveal that the kinetics of the activation reaction of sphalerite with $\mathrm{Cu}(\mathrm{OH})_{2}$ is slower probably due to the low activity of the $\mathrm{Cu}$ (II) species in solution, which are, the ones adsorbing on the mineral surface to exchange with the zinc, which is released to the solution according to the following reactions [8]:

$n \mathrm{ZnS}+x \mathrm{Cu}(\mathrm{OH})_{2 \text { (precipitate })}=(\mathrm{ZnS})_{n} \cdot x \mathrm{Cu}(\mathrm{OH})_{2(\text { surface })}$

The $\mathrm{Cu}(\mathrm{II})$ of the hydroxide is then exchange with the $\mathrm{Zn}$ (II) of the sulfide:

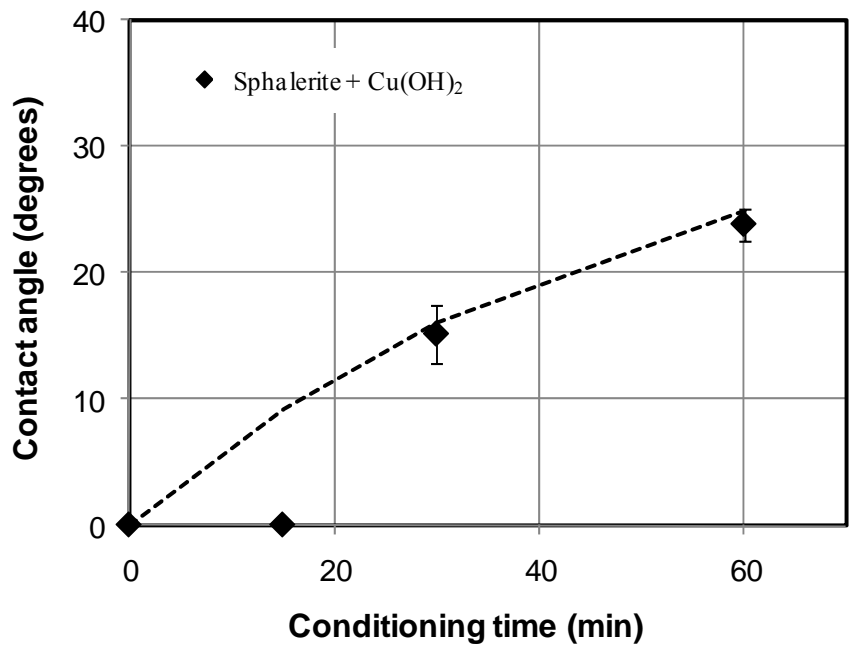

Fig. (7). Effect of conditioning time on the development of the hydrophobic character of sphalerite activated with $5 \mathrm{mg} / \mathrm{L} \mathrm{Cu}$ (II) in the form of $\mathrm{Cu}(\mathrm{OH})_{2}$. The dotted line was obtained with Equation (9). 


$$
(\mathrm{ZnS})_{n} \cdot x \mathrm{Cu}(\mathrm{OH})_{2(\text { surface })}=\mathrm{Zn}_{n-\chi} \mathrm{Cu}_{\chi} S_{n} \cdot x \mathrm{Zn}(\mathrm{OH})_{2(\text { surface })}
$$

Fig. (7) presents contact angles measured with $5 \mathrm{mg} \mathrm{L}^{-1}$ copper concentration and conditioning times of 15, 30 and 60 minutes, clearly showing that hydrophobicity increases with time due to copper incorporation into the mineral lattice and the corresponding oxidation of the sulfide $\left(\mathrm{S}^{2-}\right)$ to disulphide $\left(\mathrm{S}_{2}{ }^{2-}\right)$ and elemental sulfur (S). The dotted line is obtained by using Equation (9) with the values of $\mathrm{k}$ and $\theta_{\infty}$ presented above. As noted in the figure, the equation describes well the experimental data $\left(R^{2}=0.97\right)$, even though the parameters of the equation were obtained with data gather under slightly acid conditions where $\mathrm{Cu}^{2+}$ is the predominant copper species, while the data in Fig. (7) was obtained at $\mathrm{pH}$ 9 , where the predominant copper species is the precipitated hydroxide.

\section{CONCLUSIONS}

Based on the results obtained in the present work, the following conclusions can be drawn.

Sphalerite develops natural hydrophobicity upon activation due to the reduction that $\mathrm{Cu}$ (II) undergoes when replaces $\mathrm{Zn}$ from the external layers of the mineral lattice, which is accompanied by the oxidation of the sulphide $\left(\mathrm{S}^{2-}\right)$ of the mineral lattice to a polysulfide $\left(\mathrm{S}_{\mathrm{n}}{ }^{2-}\right)$ and elemental sulfur (S).

The activation kinetics appears to obey the second order model reported by Finkelstein (1997), which states that the rate of adsorption (i.e., hydrophobization) depends on both copper concentration in the solution and availability of zinc sites on the external layers of the mineral lattice.

The kinetics of the activation reaction is favored when slightly acid conditions are used due to $\mathrm{Cu}^{2+}$ being the predominant copper species, although the model developed is capable of describing qualitatively the kinetics of the process carried out under slightly alkaline conditions ( $\mathrm{pH} 9$ ), where the predominant copper species is the solid hydroxide.

\section{CONFLICT OF INTEREST}

The authors confirm that this article content has no conflicts of interest.

\section{ACKNOWLEDGEMENTS}

The authors are grateful to the technical and administrative personnel of Cinvestav-IPN and to Conacyt (México) for the financial support received.

\section{REFERENCES}

[1] A.P. Chandra, and A.R. Gerson, "A review of the fundamental studies of the copper activation mechanisms for selective flotation of the sulfide minerals, sphalerite and pyrite", Adv. Colloid Interface Sci. , vol. 145, pp. 97-110, 2009.

[2] D. Fornasiero, and J. Ralston, "Effect of surface oxide/hydroxide products on the collectorless flotation of sopper-activated sphalerite", Int. J. Miner. Process., vol. 78, pp. 231-237, 2006.

[3] N.P. Finkelstein, "The activation of sulphide minerals for flotation: a review”, Int. J. Miner. Process., vol. 52, pp. 81-120, 1997.

[4] T.T. Chau, "A review of techniques for measurement of contact angles and their applicability on mineral surfaces", Miner. Eng., vol. 22, pp. 213-219, 2009.

[5] E. Peters, "Direct leaching of sulfides: chemistry and applications", Metallogr Trans. B, vol. 7, pp. 505-517, 1976.

[6] S. Jain and D.W. Fuerstenau, Flotation of Sulphide Mineral. Elsevier: Amsterdam, 1985.

[7] X. Wang, E. Forssberg, and N.J. Bolin, "Effect of oxygen on Cu(II) adsorption by sphalerite in acid and neutral $\mathrm{pH}$ media", Scand. J. Metallog., vol. 18, pp. 243-250, 1989.

[8] C.A. Prestidge, W.M. Skinner, J. Ralston, and R.St.C. Smart, "Copper(II) activation and cyanide deactivation of zinc sulphide under mildly alkaline conditions", Appl. Surf. Sci., vol. 108, pp. 333-344, 1997.

[9] I.J. Kartio, C.I. Basilio, and R.-H. Yoon, "An XPS study of sphalerite activation by copper”, Langmuir, vol.14, pp. 5274-5278, 1998. 